\title{
Reactions of Strong Bases with Vinyl Fluoride Formation and Characterization of 1-Fluorovinyl Anion and the Fluoride-Acetylene Hydrogen-bonded Complex
}

\author{
John J. Rabasco and Steven R. Kass \\ Department of Chemistry, University of Minnesota, Minneapolis, Minnesota, USA
}

Vinyl fluoride reacts with strong bases to afford 1-fluorovinyl anion (1a) and a fluorideacetylene cluster (1b). The former ion can be prepared independently, and cleanly, by the fluorodesilylation of 1-(trimethylsilyl)fluoroethylene. Reactions of la are reported, and its proton affinity is assigned $\left(387 \pm 3 \mathrm{kcal} \mathrm{mol}^{-1}\right)$. Vinyl fluoride is $22 \mathrm{kcal} \mathrm{mol}^{-1}$ more acidic than ethylene. This unusually large substituent effect is reproduced by ab initio calculations, and can be accounted for by geometric changes which minimize the electron-electron repulsion in 1a. Computations on 2-fluorovinyl anions (1c and 1d) have also been carried out, and both ions are only slightly less stable than 1a. The cis isomer (1c) has a larger barrier for fluoride elimination and is a reasonable target for preparation. (] Am Soc Mass Spectrom 1992, 3, 91-98)

S ubstituent effects have been examined extensively in the gas phase and have provided a wealth of data [1]. Relatively few studies, however, have involved substituents directly bound to a carbanionic center. This is surprising because one would anticipate the largest perturbations in these instances. As a result, we recently investigated a series of 1-substituted allyl anions which contain $\sigma$ withdrawing and $\pi$-donating groups, i.e., $\mathrm{OCH}_{3}$, $\mathrm{N}\left(\mathrm{CH}_{3}\right)_{2}$ and $\mathrm{F}$ [2]. These electronegative substituents were chosen because they can stabilize carbanions inductively and destabilize them via electron-electron repulsion. The two conflicting tendencies offset each other, as they do in the analogous benzyl and acetonitrile derivatives $[3,4],{ }^{1}$ in that the basicities are essentially the same as the unsubstituted ion. One exception to this trend is $\mathrm{CHF}=\mathrm{C}\left(\mathrm{CH}_{3}\right) \mathrm{O}^{-}[5]$, but in this case the lone-pair-lone-pair repulsive interaction is significantly diminished because the negative charge is located primarily on the oxygen atom. To ascertain the generality of these effects and explore them further, we decided to investigate a localized anion. Vinyl fluoride (1) is of interest in this regard.

More than a decade ago, Sullivan and Beauchamp [6] reported that vinyl fluoride can be deprotonated

Address reprint requests to Steven R. Kass, Department of Chemistry, University of Minnesota, Minneapolis, MN 55455.

${ }^{1}$ Ail cited acidities, unless otherwise noted, come from ref 4. by strong bases. The resulting M-1 ion was assumed to be the conjugate base $\left(\mathrm{CH}_{2}=\mathrm{CF}^{-}, 1 \mathrm{a}\right)$, but this structural assignment was based on nothing more than expectation and intuition. In subsequent years, McMahon and co-workers [7] found that fluoride readily hydrogen-bonds to a wide variety of compounds including simple olefins. This information, along with ab initio molecular orbital calculations, led Roy and McMahon [7b] to reevaluate some of the early ion-molecule reaction literature. In particular, they suggested that bases induce an elimination reaction in 1 , and that the resulting $M-1$ ion is a fluoride-acetylene hydrogen-bonded complex $\left(\mathrm{H}-\mathrm{C} \equiv \mathrm{C}-\mathrm{H} \cdots \mathrm{F}^{-}, \mathbf{1 b}\right)$. In this article these two apparently conflicting proposals are resolved, and structural, reactivity, and thermodynamic data on the M-1 ion derived from vinyl fluoride are presented.

\section{Experimental}

These studies were carried out with a variable-temperature flowing afterglow apparatus which has previously been described [8]. Helium was employed as the buffer gas and flow tube pressures of 0.3-0.4 torr were utilized during these room temperature experiments. Reactant ions were generated by electron impact on $\mathrm{NH}_{3}, \mathrm{~N}_{2} \mathrm{O}$ and $\mathrm{CH}_{4}(\sim 1 ; 2), \mathrm{N}_{2} \mathrm{O}, \mathrm{MeONO}$ (generated in situ) [9], (t-BuO) ${ }_{2}$, and $\mathrm{NF}_{3}$ to afford $\mathrm{NH}_{2}^{-}, \mathrm{OH}^{-}, \mathrm{O}^{-}, \mathrm{MeO}^{-}, \mathrm{t}^{-\mathrm{BuO}^{-}}$, and $\mathrm{F}^{-}$, respec- 
tively. All other ions were prepared by proton abstraction from the corresponding conjugate acid unless otherwise noted.

All of the compounds used in this study were obtained from commercial suppliers except for 1-(trimethylsilyl)fluoroethylene $\left[\mathrm{CH}_{2}=\mathrm{C}(\mathrm{TMS}) \mathrm{F}, 2\right]$. This material has not been synthesized previously despite several reported attempts [10]. We found that 2 can be prepared, however, by reacting the Grignard reagent of 1-(trimethylsilyl)bromoethylene $\left[\mathrm{CH}_{2}=\mathrm{C}\right.$ (TMS)Br] [11] with $N$-fluoro-2,4,6-trimethylpyridinium trifluoromethanesulfonate (triflate) [12] as follows: 1,2-dibromoethane $(0.2 \mathrm{~g})$ was added to a solution of dry tetrahydrofuran (THF, $10 \mathrm{~mL}$ ) and $\mathrm{Mg}$ turnings $(0.92$ $\mathrm{g}, 38 \mathrm{mmol}$ ) under a $\mathrm{N}_{2}$ atmosphere. Upon initiation of Grignard formation, $\mathrm{CH}_{2}=\mathrm{C}$ (TMS) $\mathrm{Br}(5.0 \mathrm{~g}, 28$ $\mathrm{mmol}$ ) in THF ( $8 \mathrm{~mL}$ ) was added dropwise so as to maintain a gentle reflux. The stirred solution was heated for $1 \mathrm{~h}$ at $65{ }^{\circ} \mathrm{C}$, cooled to $0{ }^{\circ} \mathrm{C}$, and diluted with THF $(10 \mathrm{~mL})$. N-Fluoro-2,4,6-trimethylpyridinium triflate $(8.1 \mathrm{~g}, 28 \mathrm{mmol})$ was then added in several portions over $20 \mathrm{~min}$, and the resulting solution was kept at $0{ }^{\circ} \mathrm{C}$ for $30 \mathrm{~min}$ and then at room temperature for $1 \mathrm{~h}$. The reaction mixture was quenched with $5 \%$ aqueous $\mathrm{HCl}(50 \mathrm{~mL})$ and diluted with pentane $(50 \mathrm{~mL})$. The aqueous layer was extracted with pentane $(2 \times 15 \mathrm{~mL})$ and the combined organic material was rigorously washed with $\mathrm{H}_{2} \mathrm{O}$ $(12 \times 40 \mathrm{~mL})$ to remove the residual THF. The resulting solution was dried over anhydrous $\mathrm{MgSO}_{4}$, concentrated via an atmospheric distillation (Vigreaux column), and the residue was found to consist of a $\sim 2: 1$ ratio of 1 -(trimethylsilyl)fluoroethylene to vinyltrimethylsilane. Preparative gas chromatography $\left(20 \% \mathrm{SE}-30,30^{\circ} \mathrm{C}\right.$ ) afforded $550 \mathrm{mg}$ of the volatile product (2, boiling point $\sim 65^{\circ} \mathrm{C}$ estimated) in a nonoptimized yield of $17 \%$ (note: this reaction is much less efficient in $\mathrm{Et}_{2} \mathrm{O}$ ). ${ }^{1} \mathrm{H}$-nuclear magnetic resonance (NMR) $\left(300 \mathrm{MHz}, \mathrm{CDCl}_{3}\right) \delta 5.23(1 \mathrm{H}, \mathrm{dd}, \mathrm{J}=33.6$ and $2.9 \mathrm{~Hz}$, cis $\mathrm{CH}=\mathrm{CF}), 4.74(1 \mathrm{H}, \mathrm{dd}, \mathrm{J}=62.3$ and $2.9 \mathrm{~Hz}$, trans $\mathrm{CH}=\mathrm{CF}), 0.17\left(9 \mathrm{H}, \mathrm{s},\left(\mathrm{CH}_{3}\right)_{3} \mathrm{Si}\right) ;{ }^{13} \mathrm{C}-$ NMR (75.4 MHz, $\left.\mathrm{CDCl}_{3}\right)$ o 176.1 (d, $282 \mathrm{~Hz}$, $=\mathrm{C}$ (TMS)F), 105.2 (d, $8.3 \mathrm{~Hz}, \mathrm{C}=\mathrm{C}$ (TMS)F), -2.76 (s, $\left.\left(\mathrm{CH}_{3}\right)_{3} \mathrm{Si}\right) ;{ }^{19} \mathrm{~F}-\mathrm{NMR}\left(282 \mathrm{MHz}, \mathrm{CFCl}_{3}\right) \delta-105.1$ (dd, $\mathrm{J}=61.0$ and $33.6 \mathrm{~Hz}$ ); mass spectrum calculated for $\mathrm{C}_{5} \mathrm{H}_{11} \mathrm{FSi}\left(\mathrm{M}^{+}\right) \mathrm{m} / \mathrm{z}$ 118.0612, found 118.0661.

\section{Results}

Vinyl fluoride reacts with a variety of bases to afford, among other products, an M-1 ion ( $m / z$ 45). The structure of this species need not be the same in every case, and therefore several diagnostic reactions were carried out in a number of instances. The results are presented below, and for the most part are organized in terms of the reacting base which was used.
Amide

Vinyl fluoride reacts readily with $\mathrm{NH}_{2}^{-}$to afford fluoride $(m / z 19)$, a trace of acetylide $\left(\mathrm{HC}_{2}^{-}, m / z 25\right)$, a fluoride-ammonia cluster $(m / z 36)$, and an M-1 ion $(m / z 45 \text {, eq } 1)^{2}$

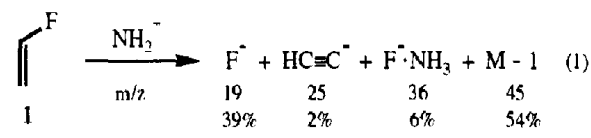

Methanol-OD $\left(\Delta \mathrm{H}_{\text {acid }}=382.5 \mathrm{kcal} \mathrm{mol}^{-1}\right)[4]$ interacts with the $\mathrm{M}-1$ ion to produce methoxide and fluoride-methanol clusters. The relative ratios of these products were not determined because the fluorideammonia cluster and a background ion at $\mathrm{m} / \mathrm{z} 37$ $\left(\mathrm{F}^{-} \cdot \mathrm{H}_{2} \mathrm{O}\right)$ both react with methanol to afford $\mathrm{F}^{-}$. $\mathrm{MeOH}^{3}$ Carbon dioxide, carbonyl sulfide, carbon disulfide, and sulfur dioxide react with the $\mathrm{m} / \mathrm{z} 45$ ion (eqs 2-5),

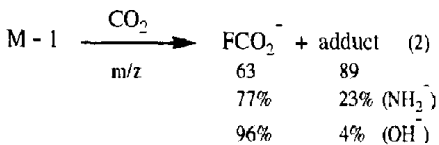

$$
\begin{aligned}
& \underset{\mathrm{m} / \mathrm{z}}{\mathrm{COS}} \prod_{77} \prod_{27 \%}^{\mathrm{s}^{-}}+\underset{59 \%}{\mathrm{FCOS}^{-}}+\underset{105}{14 \%\left(\mathrm{NH}_{2}\right)}
\end{aligned}
$$

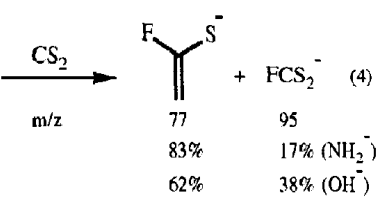

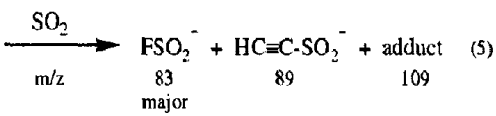

whereas $\mathrm{N}_{2} \mathrm{O}$ and $\mathrm{O}_{2}$ do not. The product distributions given in eqs 2-4 vary depending upon the base which is used to generate the M-1 ion. It is also worth noting that the reaction with $\mathrm{CS}_{2}$ can potentially lead to two products, sulfur-atom transfer and hydride transfer $\left(\mathrm{C}_{2} \mathrm{H}_{2} \mathrm{FS}^{-}\right.$and $\left.\mathrm{HCS}_{2}^{-}\right)$, with the same nominal mass. They can be distinguished on the basis of their different isotope ratios at $m / z 77,78$, and 79

\footnotetext{
${ }^{2}$ All product distributions (branching ratios) were obtained by extrapolating back to zero flow of the neutral reagent.

The formation of $\mathrm{NH}_{2}^{-}$is always accompanied by $\mathrm{OH}^{-}$in our apparatus due to the presence of trace water and/or oxygen impurtties. Since hydroxdde reacts with 1 to afford, in part, a fluoride-water hydrogen-bonded complex, this ion is always present to some degree.
} 
(calculated 100:2.7:8.8 for $\mathrm{HCS}_{\overrightarrow{2}}$ and 100:3.0:4.4 for $\mathrm{C}_{2} \mathrm{HFS}^{-}$; observed 100:3.5:4.8), but the presence of some $\mathrm{HCS}_{2}^{-}$cannot be completely ruled out.

\section{Hydroxide}

An abundant M-1 ion, an equal amount of $\mathrm{F}^{-} \cdot \mathrm{H}_{2} \mathrm{O}$, and traces of $\mathrm{F}^{-}$and acetaldehyde enolate are produced from the reaction of $\mathrm{OH}^{-}$with 1 (eq 6).

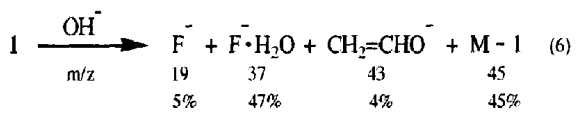

When this mixture of ions is allowed to interact with $\mathrm{D}_{2} \mathrm{O}$, fluorobenzene, MeOD, and $\mathrm{t}-\mathrm{BuOD}\left(\Delta \mathrm{H}_{\text {acid }}=\right.$ $392.0,387.2,382.5$, and $\left.374.6 \mathrm{kcal} \mathrm{mol}^{-1}\right),[4]$, the conjugate bases of all four reagents and cluster ions, e.g., $\mathrm{F}^{-} \cdot \mathrm{D}_{2} \mathrm{O}$, are generated. The reaction with $\mathrm{D}_{2} \mathrm{O}$ is very inefficient, and only a trace of $\mathrm{OD}^{-}$and a small amount of $\mathrm{DC} \equiv \mathrm{CH} \cdots \mathrm{F}^{-}$are observed. Nitrous oxide and molecular oxygen do not react with the $\mathrm{M}-1$ ion, but $\mathrm{CO}_{2}, \mathrm{COS}$, and $\mathrm{CS}_{2}$ give the products shown in eqs 2-4. All of these reactions were also examined at $200^{\circ} \mathrm{C}$, and the only noted difference is that hydride transfer appears to be the favored product with carbon disulfide rather than sulfur-atom transfer. This conclusion is based upon the isotope distribution, which is 100:3.6:7.8 at $m / z 77,78$, and 79.

\section{Methoxide}

A facile reaction occurs between 1 and $\mathrm{MeO}^{-}$, but it is difficult to generate the M-1 ion and only a little is formed (eq 7).

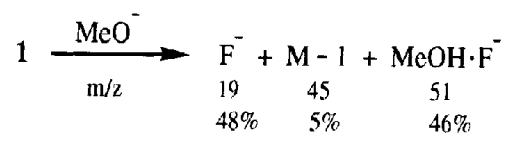

The intensity of this ion was maximized, but under the optimum conditions for its formation a significant amount of methoxide was also present in the flow tube. This made it difficult to study the reactivity of the M-1 ion, nevertheless, we were able to show that it does not react via sulfur-atom transfer with $\mathrm{COS}$. At higher temperatures, such as $200^{\circ} \mathrm{C}$, it is considerably easier to generate the $\mathrm{M}-1$ ion, and some sulfuratom transfer occurs with COS.

\section{Miscellaneous Bases}

Strong bases such as fluorophenide and the atomic oxygen ion $\left[\Delta \mathrm{H}_{\text {acid }}(\mathrm{HO})=382.2 \mathrm{kcal} \mathrm{mol}^{-1}\right.$ ) [4] react with vinyl fluoride to afford an M-1 ion. In the former case, the reactivity with $\operatorname{COS}$ was found to be very similar to the ion generated from $\mathrm{OH}^{-}$(eq 3). In the latter instance, the reactivity was not probed because the dominant product is an M-2 ion ( $m / z 44$, eq 8 ).

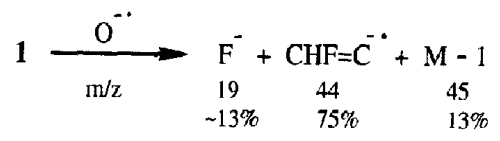

Weaker bases such as $\mathrm{F}^{-}, \mathrm{t}-\mathrm{BuO}^{-}$, and $\mathrm{EtO}^{-}$were also examined, but they do not react with 1 to give an ion at $m / z 45$.

\section{1-(Trimethylsilyl)fluoroethylene (2)}

Fluoride reacts cleanly and efficiently with 2 to afford a major product at $m / z 45$, and two minor ions at $m / z 91$ and 111 (eq 9).

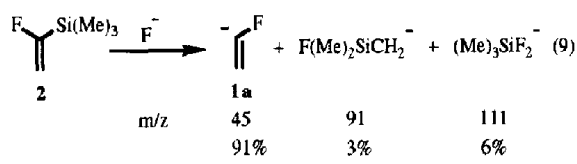

The first of these species readily deprotonates MeOD and fluorobenzene, but inefficiently abstracts a proton from $\mathrm{H}_{2} \mathrm{O}$ to yield only a little $\mathrm{OH}^{-}$. Likewise, deuterium oxide reacts with the $m / z 45$ ion to afford a trace of $\mathrm{OD}^{-}(\mathrm{m} / \mathrm{z} 18)$, a small amount of a single hydrogen/deuterium exchange $(m / z 46)$, and $\mathrm{F}^{-}$. $\mathrm{D}_{2} \mathrm{O}(\mathrm{m} / z 39)$ as the dominant product. If the reaction with $\mathrm{H}_{2} \mathrm{O}$ is carried out to partial conversion and the remaining $\mathrm{m} / \mathrm{z} 45$ ion is interrogated with $\mathrm{CS}_{2}$, two products are formed as in eq 4. Ion 1a, however, reacts with $\mathrm{CO}_{2}, \mathrm{COS}, \mathrm{CS}_{2}$, and $\mathrm{SO}_{2}$ (eqs 10-13)

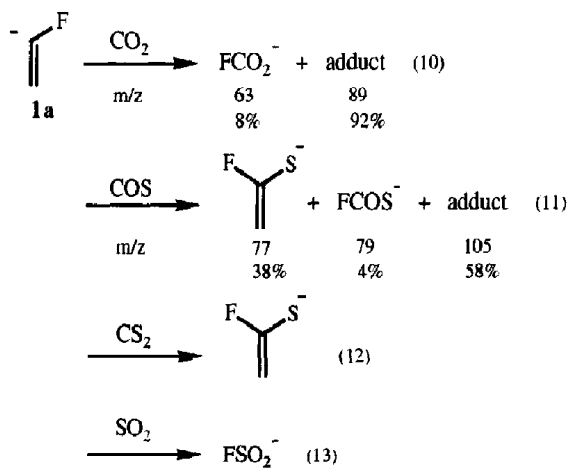

in a different fashion than the $\mathrm{M}-1$ generated by proton abstraction from 1 . In particular, the former does not undergo any fluoride transfer with $\mathrm{CS}_{2}$, and 
only minor amounts with $\mathrm{CO}_{2}$ and $\mathrm{COS}$. The reaction with sulfur dioxide is also characteristic.

\section{Calculations}

$\mathrm{Ab}$ initio molecular orbital calculations have previously been carried out on the conjugate base of vinyl fluoride (1a), and the isomeric fluoride-acetylene hydrogen-bonded cluster (1b) [7b]. These computations have been repeated and supplemented at a signifcantly higher level of theory using Gaussian 90 [13]. Geometries were optimized at Hartree-Fock and correlated levels using the $6-31+\mathrm{G}^{*}$ and $\mathrm{MP} 2 / 6-31+\mathrm{G}^{*}$ basis sets (Table 1) [14]. ${ }^{4}$ Both methods include polarization functions and diffuse orbitals, which are necessary to adequately describe negative ions and molecules with atoms of differing electronegativity [15]. The resulting geometries are in good accord with the previous work on acetylene, vinyl fluoride, and 1-fluorovinyl anion (1a), but differ substantially for the cis and trans-2-fluorovinyl anions (1c and 1d) and their respective elimination transition states $\left(\right.$ TS $_{\text {syn }}$ and $\left.\mathbf{T S}_{\text {anti }}\right)$. Analytical frequencies were computed $\left(6-31+G^{*}\right)$ to ensure that each structure corresponds to a minimum on the potential energy surface (no imaginary frequencies) or a transition state (one negative frequency), and to obtain zero-point vibrational energies. Electron correlation was incorporated into the energy calculations by using second-, third-, or fourth-order M $\phi$ ller-Plesset perturbation theory [14d,e]. Larger basis sets were also used in a few cases to obtain more reliable energies (Table 2).

\section{Discussion}

Vinyl fluoride can be deprotonated by strong bases such as amide or hydroxide. Two different structures have previously been suggested for the resulting $\mathrm{M}-1$ ion $\left(\mathrm{C}_{2} \mathrm{H}_{2} \mathrm{~F}^{-}, m / z 45\right)$, but neither was examined experimentally. Sullivan and Beauchamp [6] proposed that the product is 1-fluorovinyl anion (1a), and that it arises from simple acid-base chemistry. Almost a decade later, Roy and McMahon [7b] postulated that the M-1 ion is a hydrogen-bonded structure, $\mathrm{H}-\mathrm{C} \equiv \mathrm{C}-\mathrm{H} \cdots \mathrm{F}^{-}(\mathbf{1 b})$, and that it comes from an elimination reaction. These two isomers have very different bonding arrangements, and should be readily distinguished from each other. For example, it is reasonable to anticipate that $\mathbf{1 b}$ will undergo facile solvent switching reactions (fluoride transfer) since it is a cluster ion, whereas the covalently bound species, 1a, will not. The latter ion, on the other hand, should undergo characteristic reactions with reagents such as $\mathrm{CO}_{2}, \mathrm{COS}, \mathrm{CS}_{2}$, and $\mathrm{SO}_{2}$, which $\mathbf{1 b}$ is incapable of

\footnotetext{
${ }^{4}$ In this article we abbreviate MP $x / 6-31+\mathrm{G}^{*} / / 6-31+\mathrm{G}^{*}$ and MP2/6$31+\mathrm{G}^{*} / / \mathrm{MP} 2 / 6-31+\mathrm{G}^{*}$ simply by MP $x$ and $\mathrm{MP}^{2} / 6-31+\mathrm{G}^{*}$, where $x=2,3$, or 4 .
}

undergoing [16]..$^{5}$ Based on these expectations, we suggest that the formation of sulfur-atom and fluoride transfer products (eqs 3 and 4) indicate that both 1a and $\mathbf{~} \mathrm{b}$ are formed from the reactions of strong bases with vinyl fluoride. ${ }^{6}$ Support for this conclusion was obtained by carrying out an independent preparation of 1a (eq 9) $[8,17]$ and probing its reactivity. ${ }^{7}$ Consistent with our interpretation, 1a generated by the fluorodesilylation of 2 undergoes sulfur-atom transfer with $\mathrm{COS}$ and $\mathrm{CS}_{2}$, and only leads to a minor amount of fluoride transfer with the former reagent.

The acidity of vinyl fluoride can be assigned having established the structure of 1a. Strong bases such as amide, hydroxide, and fluorophenide deprotonate 1, as ascertained by the reactivity of the conjugate base, whereas methoxide and weaker bases do not. At elevated temperatures, $200^{\circ} \mathrm{C}, \mathrm{MeO}^{-}$reacts with 1 to afford some 1-fluorovinyl anion. This result is in accord with the earlier work of Sullivan and Beauchamp [6], and clearly indicates that vinyl fluoride is less acidic than methanol. The conjugate base, 1a, will abstract a proton from fluorobenzene, methanol, and stronger acids, but is extremely inefficient in deprotonating $\mathrm{H}_{2} \mathrm{O}$. Therefore, the acidity of vinyl fluoride must be very similar to fluorobenzene's, and we assign $\Delta \mathrm{H}_{\text {acid }}(1)=387 \pm 3 \mathrm{kcal} \mathrm{mol}^{-1}$. This represents a remarkable acidifying effect for a fluorine atom, 22 $\mathrm{kcal} \mathrm{mol}{ }^{-1}[18]^{8}$ and is far larger than any other which has been reported. It also stands in sharp contrast to allyl and benzyl fluoride which are no more acidic than their corresponding hydrocarbons $[2,3]$.

To gain further insight into the unusually large substituent effect observed for vinyl fluoride, ab initio molecular orbital calculations on $\mathrm{F}^{-}$, acetylene, 1, 1a, and $1 \mathrm{~b}$ were carried out using Gaussian 90 (Tables 1 and 2) [13]. Full geometry optimizations were performed at Hartree-Fock and correlated levels using the $6-31+G^{*}$ and $M P 2 / 6-31+G^{*}$ basis sets [14] and standard gradient techniques. Each structure was characterized by its vibrational frequency, and electron correlation was accounted for in the energy calculations. The resulting deprotonation energy for vinyl fluoride was found to be in very good agreement with experiment upon correction for the zero-point vibrational energy (384.5 (MP2), 385.1 (MP2/6-31 + G*), and $387 \pm 3$ (experimental) $\mathrm{kcal} \mathrm{mol}^{-1}$ ). This level of accuracy $\left( \pm 2-3 \mathrm{kcal} \mathrm{mol}^{-1}\right)$ is fairly common for calculations of this type on a wide variety of compounds. The dissociation energy of the fluoride-

\footnotetext{
${ }^{5}$ For a description of the characteristic reactions these reagents undergo, see ref 16.

The formation of an adduct-HF ion in the $\mathrm{SO}_{2}$ reaction is also consistent with the presence of $1 \mathrm{a}$.

Fluorodesilylation reactions have been shown to be useful for the preparation of carbanions in a regiospecific and stereospecific man ner. For further details see ref 17

${ }^{8}$ The acidity of ethylene has recently been measured to be $409.4 \mathrm{kcal}$ $\mathrm{mol}^{-1}$. See ref 18 .
} 
acetylene hydrogen-bonded complex (1b, eq 14),

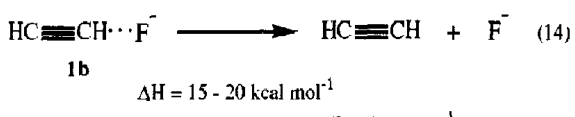

calculated: $19.4\left(6-31+\mathrm{G}^{*}\right), 20.2(\mathrm{MP} 2) \mathrm{kcal} \mathrm{mol}$

the relative stabilities of $1 \mathrm{a}$ and $\mathbf{1 b}$ (experimental $\Delta \mathrm{H}_{\mathrm{f}}$ (1a) $=-12 \pm 3$ and $\Delta \mathrm{H}_{\mathrm{f}}(\mathbf{1 b})=-20--25 \mathrm{kcal} \mathrm{mol}^{-1}$; calculated $\Delta \mathrm{H}_{\mathrm{f}}(1 \mathrm{a}-1 \mathrm{~b})=13.2$ and $22.0 \mathrm{kcal} \mathrm{mol}^{-1}$ at the 6-31+ G* and MP2 levels), and the reaction enthalpy for the process shown in eq 15

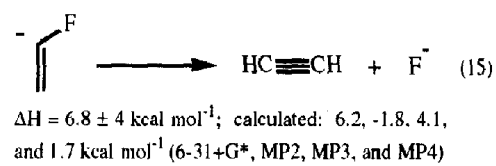

can also be reproduced $[4,7 \mathrm{~b}]$. The experimental values, however, are not known very precisely, and

Table 1. Calculated 6-31+ $G^{*}$ and $M P 2 / 6-31+G^{*}$ geometries for acetylene, fluoride-acetylene, vinyl fluoride, 1-fluorovinyl anion, and 2-fluorovinyl anion ${ }^{\mathrm{a}}$

\begin{tabular}{|c|c|c|c|c|c|}
\hline \multirow[t]{4}{*}{$\mathrm{H}-\mathrm{C} \equiv \mathrm{C} \cdot \mathrm{H}$} & $\mathrm{C} \cdot \mathrm{C}$ & $1.188(1.219)[1.203]$ & \multirow{2}{*}{$\begin{array}{c}\mathrm{H}_{1}-\mathrm{C}=\mathrm{C}-\mathrm{H}_{2} \cdot \cdot \mathrm{F} \\
\mathbf{1 b}\end{array}$} & $\mathrm{C}-\mathrm{C}$ & 1.199 \\
\hline & \multirow[t]{3}{*}{$\mathrm{C}-\mathrm{H}$} & \multirow[t]{3}{*}{$1.058(1.069)[1.061]$} & & $\mathrm{C}-\mathrm{H}_{1}$ & 1.057 \\
\hline & & & & C. $\mathrm{H}_{2}$ & 1.122 \\
\hline & & & & F- $\mathrm{H}_{2}$ & 1.564 \\
\hline \multirow{9}{*}{${ }_{\mathrm{H}}^{\mathrm{F}}=\mathrm{C}_{\mathrm{H}}^{\mathrm{H}}$} & $\mathrm{C}-\mathrm{C}$ & $1.311(1.328)[1.330]$ & \multirow{9}{*}{$\underbrace{F_{1}}_{-}=\sum_{C^{\prime}}^{H_{\beta c}}$} & $\mathrm{C}-\mathrm{C}$ & $1.347(1.358)$ \\
\hline & $C-F$ & $1.333(1.364)[1.351]$ & & $C-F$ & $1.436(1.483)$ \\
\hline & $\mathrm{C}-\mathrm{H}_{\alpha}$ & $1.072(1.084)[1.107]$ & & $\mathrm{C}-\mathrm{H}_{\mathrm{pc}}$ & $1.085(1.096)$ \\
\hline & $\mathrm{C}-\mathrm{H}_{\mathrm{pc}}$ & $1.074(1.083)[1.108]$ & & $\mathrm{C}-\mathrm{H}_{\beta \mathrm{r}}$ & $1.079(1.088)$ \\
\hline & $\mathrm{C}-\mathrm{H}_{\beta 1}$ & $1.073(1.082)[1.097]$ & & $\mathrm{FCC}$ & $108.3(107.1)$ \\
\hline & FCC & $122.1(121.5)[121.5]$ & & $\mathrm{CCH}_{\mathrm{BC}}$ & $118.9(118.2)$ \\
\hline & $\mathrm{CCH}_{\alpha}$ & $126.2(127.0)[130.8]$ & & $\mathrm{CCH}_{\beta 1}$ & $123.8(124.1)$ \\
\hline & $\mathrm{CCH}_{\beta c}$ & $121.6(121.6)[120.4]$ & & & \\
\hline & $\mathrm{CCH}_{\beta \mathrm{t}}$ & $119.5(119.1)[118.7]$ & & & \\
\hline \multirow{7}{*}{$\sum_{\mathrm{H}_{\alpha}}^{\mathrm{F}}=\mathrm{C}_{1 \mathrm{H}}^{-}$} & $\mathrm{C}-\mathrm{C}$ & $1.318(1.322)$ & \multirow{7}{*}{$\underset{\mathrm{H}_{\alpha}}{\mathrm{F}}=\mathrm{C}$} & $\mathrm{C}-\mathrm{C}$ & $1.315( \pm .311)$ \\
\hline & $C-F$ & $1.403(1.449)$ & & $C-F$ & $1.433(1.534)$ \\
\hline & $\mathrm{C}-\mathrm{H}_{\alpha}$ & $1.083(1.097)$ & & $\mathrm{c}-\mathrm{H}_{\alpha}$ & $1.076(1.086)$ \\
\hline & $\mathrm{C}-\mathrm{H}_{\beta c}$ & $1.098(1.105)$ & & $\mathrm{C}-\mathrm{H}_{\beta \mathrm{c}}$ & $1.096(1.098)$ \\
\hline & $\mathrm{FCC}$ & $122.4(121.8)$ & & $\mathrm{FCC}$ & $125.5(126.6)$ \\
\hline & $\mathrm{CCH}_{\alpha}$ & $132.3(134.7)$ & & $\mathrm{CCH}_{\alpha}$ & $129.6(131.9)$ \\
\hline & $\mathrm{CCH}_{\beta \mathrm{c}}$ & $106.3(106.6)$ & & $\mathrm{CCH}_{\beta c}$ & $110.6(114.9)$ \\
\hline \multirow{7}{*}{$\sum_{\mathrm{C}=\mathrm{CS}_{\mathrm{syu}}}^{\mathrm{F}}$} & $\mathrm{C}-\mathrm{C}$ & $1235(1.260)$ & \multirow{7}{*}{$\underset{\mathrm{C}=\mathrm{C}_{-}^{\mathrm{F}}}{\mathrm{TS}_{\text {anti }}}$} & $\mathrm{C}-\mathrm{C}$ & $1.242(1.279)$ \\
\hline & $\mathrm{C}-\mathrm{F}$ & $1.832(1.735)$ & & $\mathrm{C}-\mathrm{F}$ & $1.896(1.719)$ \\
\hline & $\mathrm{C}-\mathrm{H}_{\alpha}$ & $1.060(1.083)$ & & $\mathrm{C}-\mathrm{H}_{\alpha}$ & $1.056(1.079)$ \\
\hline & $\mathrm{C}-\mathrm{H}_{\beta t}$ & $1.063(1.076)$ & & $\mathrm{C}-\mathrm{H}_{\mathrm{\beta c}}$ & $1.067(1.084)$ \\
\hline & $\mathrm{FCC}$ & $119.7(119.9)$ & & FCC & $123.9(127.1)$ \\
\hline & $\mathrm{CCH}_{\alpha}$ & $1.56 .3(150.5)$ & & $\mathrm{CCH}_{\alpha}$ & $150.4(1.38 .4)$ \\
\hline & $\mathrm{CCH}_{\beta \mathrm{t}}$ & $140.7(137.8)$ & & $\mathrm{CCH}_{\mathrm{\beta c}}$ & $133.2(127.6)$ \\
\hline
\end{tabular}

all bond lengths are in Angstroms and angles in degrees. MP2 $/ 6-31+G^{*}$ values are given in parentheses, and experimental values (ref 19 ) are in brackets (see also footnote 9 ). 
this makes it difficult to further assess these calculations. It is worth noting though, that the last comparison (eq 15) appears to be reasonably well reproduced at the Hartree-Fock and MP3 levels, but not with second- or fourth-order M $\phi$ ller-Plesset theory [19]. ${ }^{9,10}$

The calculated geometries for acetylene and vinyl

9'This trend has often been noted before. For example, see ref $15, \mathrm{p}$.
$278 f$ and ref 19 .
${ }_{10}$ The reaction enthalpy does not change very much when corre-
lated geometries (MP2/6-31+ $\left.\mathrm{G}^{*}\right)$ are employed $(7.0$ and $-1.1 \mathrm{kcal}$
$\mathrm{mol}^{-1}$ at the $6-31+\mathrm{G}^{*} / \mathrm{MP2} / 6-31+\mathrm{G}^{*}$ and $\mathrm{MP2} / 6-31+\mathrm{G}^{*}$ levels) fluoride are in excellent accord with the experimental data obtained by microwave spectroscopy (Table 1) [20]. Structures for $1 \mathrm{a}$ and $1 \mathrm{~b}$ are unknown, but the computed results are quite revealing. The fluorideacetylene complex, $\mathbf{1 b}$, is an unsymmetrical hydrogen-bonded species in which the bridging hydrogen is closer to carbon than fluorine (1.122 versus 1.564 $\AA$ ). The $\mathrm{C}-\mathrm{H}$ bond distance is perturbed, and is elongated by $0.064 \AA$. This structure seems reasonable in that the more basic fragment, acetylide $\left(\mathrm{C}_{2} \mathrm{H}^{-}\right)$ should bind the proton more tightly. Deprotonation

Table 2. Calculated energies, acidities, and heterolytic bond strengths ${ }^{\mathrm{a}}$

\begin{tabular}{|c|c|c|c|c|c|}
\hline Compound & Energy (in hartrees) ${ }^{\mathrm{b}}$ & $2 \mathrm{pe}^{\mathrm{c}}$ & & Acidity/HBS ${ }^{\mathrm{d}}$ & Expt \\
\hline $\mathrm{F}^{-}$ & $-99.418586(-99.623847)^{e}$ & & & & \\
\hline $\mathrm{H}-\mathrm{C}=\mathrm{C}-\mathrm{H}$ & $\begin{array}{c}-76.823070(-77.071132) \\
{[-76.820878]\{-77.082885\}^{\mathrm{e}}}\end{array}$ & 16.5 & & $375.0^{\mathrm{f}}$ & $376.7^{8}$ \\
\hline $\begin{array}{c}\mathrm{H}-\mathrm{C} \equiv \mathrm{C}-\mathrm{H}^{-} \cdot \mathrm{F}^{-} \\
\text {(lb) }\end{array}$ & $-176.272564(-176.727221)$ & 16.7 & & $19.4(20.2)$ & $15-20^{\mathrm{g}}$ \\
\hline $\begin{array}{c}\mathrm{CH}_{2}=\mathrm{CHF} \\
\text { (1) }\end{array}$ & $\begin{array}{c}-176.891365(-177.319142) \\
{[-176.889877]\{-177.333011\}}\end{array}$ & 26.5 & $\begin{array}{l}\alpha \\
\beta_{\text {cis }} \\
\beta_{\text {trans }}\end{array}$ & $\begin{array}{l}384.5(385.1) \\
389.7(390.1) \\
387.9(387.6)\end{array}$ & $387 \pm 3^{8}$ \\
\hline $\begin{array}{c}\mathrm{CH}_{2}=\mathrm{CF}^{-} \\
\text {(1a) }\end{array}$ & $\begin{array}{l}-176.251567(-176.692104) \\
{[-176.250573]\{-176.705049\}^{e}}\end{array}$ & 17.5 & & $\begin{array}{c}6.2(1.8\} \\
{[4.1]\{1.7\}} \\
\{7.0|<-1.1\rangle\end{array}$ & $7 \pm 4$ \\
\hline$={ }_{(1 \mathrm{c})}^{\mathrm{F}}$ & $\begin{array}{l}-176.241193(-176.683870) \\
{[-176.239974]\{-176.697104\}^{\mathrm{h}}}\end{array}$ & 17.6 & & $\begin{array}{l}-0.3(-7.0) \\
|0.3|<-6.0>\end{array}$ & \\
\hline$=\gamma^{F}$ & $\begin{array}{l}-176.242576(-176.686744) \\
{[-176.239237](-176.701078\}^{\mathrm{h}}}\end{array}$ & 17.6 & & $\begin{array}{c}0.6(-5.2) \\
\int-0.1 k<-3.5>\end{array}$ & \\
\hline$\underset{\left(\mathrm{TS}_{\mathrm{syn}}\right)}{=}$ & $\begin{array}{l}-176.210548(-176.673966) \\
{[-176.211887]\{-176.685874\}^{\mathrm{h}}}\end{array}$ & 16.1 & & $\begin{array}{l}19.2(6.2)[17.6]\{7.0\} \\
\left\{18.6 \mid<8.8>16.2^{i}\right.\end{array}$ & \\
\hline$-=_{\left(\mathrm{TS}_{\mathrm{ant}}\right)}^{\mathrm{F}}$ & $\begin{array}{l}-176.225718(-176.688078) \\
{[-176.228385](-176.700017\}^{h}}\end{array}$ & 16.3 & & $\begin{array}{l}10.6(-0.8)[6.8]\{0.7\} \\
j 10.2\}<2.0>8.9^{4}\end{array}$ & \\
\hline
\end{tabular}

All energies are in $\mathrm{kcal} \mathrm{mol}^{-1}$ except where noted.

Values were obtained with the following basis sets: $6-31+G^{*} / / 6-31+G^{*}, M P 2 / 6-31+G^{*} / / 6-31+G^{*}$ (in parentheses), $6-31+$ $\mathrm{G}^{*} / / \mathrm{MP}^{2} / 6-31+\mathrm{G}^{*}$ (in brackets), and $\mathrm{MP}^{2} / 6-31+\mathrm{G}^{*} / / \mathrm{MP}^{2} / 6-31+\mathrm{G}^{*}$ (in braces).

$\mathrm{G}^{*} / / \mathrm{MP} 2 / 6-31+\mathrm{G}^{*}$ (in brackets), and $\mathrm{MP}^{2} / 6-31+\mathrm{G}^{*} / / \mathrm{MP}^{2} / 6-31+\mathrm{G}^{*}$ (In braces).

Zero-point vibrational energies have been scaled by the customary factor of 0.89 . Acidities were calculated with the $M P 2 / 6-31+G^{*} / / 6-31+G^{*}$ and $M P 2 / 6-31+G^{*} / / M P 2 / 6-31+G^{*}$ (in parentheses) basis sets, and
include zpe corrections. Heterolytic bond strengths (HBS) are relative to $F$ and $\mathrm{C}_{2} \mathrm{H}_{2}$, and were computed with the $\mathrm{B}_{-31}+\mathrm{G}^{*} / / \mathrm{O}^{-31}+\mathrm{G}^{*}$. include zpe corrections. Heterolytic bond strengths (HBS) are relative to $F$ and $\mathrm{C}_{2} \mathrm{H}_{2}$, and were computed with the $\mathrm{B}-31+\mathrm{G}^{*} / / \mathrm{Q}-31+\mathrm{G}^{*}$,
$\left.\mathrm{MP2} / 6-31+\mathrm{G}^{*} / / 6-31+\mathrm{G}^{*}(1) \mathrm{MP} 3 / 6-31+\mathrm{G}^{*} / / 6-31+\mathrm{G}^{*}[], \mathrm{MP} 4 / 6-31+\mathrm{G}^{*} / / 6-31+\mathrm{G}^{*}\{\}, 6-31+\mathrm{G}^{*} / / \mathrm{MP}^{2} / 6-31+\mathrm{G}^{*} /\right]$, and $\mathrm{MP} 2 / 6-31$

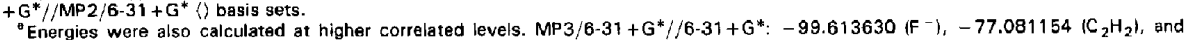
-176.701345 (1a): MP4/6-31+G*//6-31+G*: $-99.629760(\mathrm{~F}-),-77.097477\left(\mathrm{C}_{2} \mathrm{H}_{2}\right)$, and -176.729941 (1a).

f See ref 24.

${ }^{9}$ See refs 4 (acidities) and $7 \mathrm{~b}$ (hydrogen-bond strengths).

$h$ Energies were also calculated at the following levels: $6-311++G^{* * 4} / 6-31+G^{*}:-176.287120(1 \mathrm{c}),-176.287780$ (1d), -176.257473

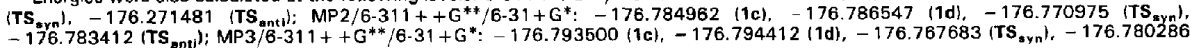

(TS 176.783.

Activation energies for the elimination of $F^{-}$. Values were calculated with the following basis sets: $6-31+G^{*} / / 6-31+G^{*}, M^{*} 2 / 6-31+$ $\mathrm{G}^{*} / / 6-31+\mathrm{G}^{*}$ (1), 6-31+G*//MP2/6-31+G* $11, \mathrm{MP2} / 6-31+\mathrm{G}^{*} / / \mathrm{MP} 2 / 6-31+\mathrm{G}^{*}\left\{1,6-311++\mathrm{G}^{* *} / 6-31+\mathrm{G}^{*} /\right], \mathrm{MP}^{*} / 6-311++$ $\mathrm{G}^{* *} / 6-31+\mathrm{G}^{*}()$, and $\mathrm{MP} 3 / 6-311++\mathrm{G}^{*+*} / 6-31+\mathrm{G}^{* * *}$. 
of 1 leads to a dramatic lengthening of the $\mathrm{C}-\mathrm{F}$ bond $(0.103 \AA)$ and a shrinking of the $\mathrm{F}-\mathrm{C}-\mathrm{C}$ angle $\left(13.8^{\circ}\right)$ in $1 a^{11,12}$. These changes help to minimize the interaction between fluorines 2 -electrons and the negative charge. This diminishes the $\pi$-donating effect of the fluorine, and leads to an especially large inductive stabilization $\left(22 \mathrm{kcal} \mathrm{mol}^{-1}\right)$. Vinyl methyl ether displays similar behavior, but the results are not as dramatic. In contrast, delocalized ions such as allyl and benzyl fluoride $\left(\mathrm{CH}_{2}=\mathrm{CH}-\mathrm{CHF}^{-}\right.$and $\mathrm{C}_{6} \mathrm{H}_{5} \mathrm{CHF}^{-}$) show no substituent effect $[2,3]$, and the stabilization energy for the fluoromethyl anion $\left(\mathrm{CH}_{2} \mathrm{~F}^{-}\right)$is much more modest $\left(7.6 \pm 4 \mathrm{kcal} \mathrm{mol}^{-1}\right)$ [21]. Presumably, this is because the repulsive lonepair-lone-pair interaction cannot be reduced as effectively as in the 1-fluorovinyl anion (1a). It is worth noting, however, that calculations indicate that $\mathrm{FCO}^{-}$ is stabilized by $48.6 \mathrm{kcal} \mathrm{mol}^{-1}$ [22].

Given the large acidifying effect of a fluorine atom at the $\alpha$-position in vinyl fluoride, it seemed worthwhile to examine the effect at the $\beta$-position. Geometry optimizations at the $6-31 \mathrm{e}+\mathrm{G}^{*}$ and MP2/6-31+ $\mathrm{G}^{*}$ levels leads to ions of vastly different structure, but the relative energies are much less sensitive to the basis set. The acidities of the $\beta$-protons are similar to each other [trans, 387.8 (MP2) and 387.4 (MP2/6-31+ $\left.\mathrm{G}^{*}\right) ; \mathrm{cis}, 389.6(\mathrm{MP} 2)$ and $390.0\left(\mathrm{MP} 2 / 6-31+\mathrm{G}^{*}\right) \mathrm{kcal}$ $\left.\mathrm{mol}^{-1}\right]$ and the more acidic site, $\beta$-trans, differs from the $\alpha$-position by only $3.4(2.4) \mathrm{kcal} \mathrm{mol}^{-1}$. These results suggest that 1a might undergo hydrogen/deuterium exchange with the appropriate reagent. However, when $1 \mathrm{a}$ is prepared independently via fluorodesilylation (eq 9) and it is allowed to react with $\mathrm{D}_{2} \mathrm{O}$, isomerization to $\mathbf{1 b}$ occurs (as verified by its reaction with $\mathrm{CS}_{2}$ ). A reasonable mechanism for this process is given in Scheme I, and it may or may not involve a $\beta$-fluorovinyl anion (1c and 1d). The stability of these species was evaluated by locating the transition states for the elimination of $\mathrm{F}^{-}$. The barriers vary considerably with the extent of electron correlation, but it appears, as previously reported [23] that the activation energy for syn-elimination is greater than for the anti pathway by $\sim 8 \mathrm{kcal} \mathrm{mol}^{-1}$. It also seems likely that the $\beta$-trans anion (1d) will be unstable with respect to fluoride loss at room temperature.

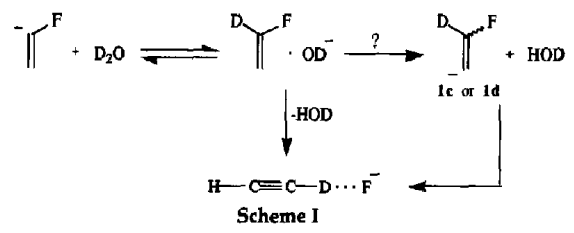

\footnotetext{
${ }^{11} 6-31+G^{*}$ geometries are cited in the text to be consistent with the results for $1 \mathrm{~b}$. The MP2/6-31+G* geometry, however, is very similar, and leads to a lengthening of the $\mathrm{C}-\mathrm{F}$ bond of $0.119 \AA$ and $a$ reduction of the FCC angle of $14.4^{\circ}$,
}

12 Observations of this sort have been noted previously. See ref $7 \mathrm{~b}$.
The $\beta$-cis isomer (1c) may also be unstable at room temperature, but given the larger barrier it undoubtedly can be generated. In fact, we cannot entirely rule out the possibility that some of this ion is formed when vinyl fluoride is deprotonated with strong bases. Finally, it is interesting but puzzling to note that the conjugate base of acrylonitrile $\left(\mathrm{CH}_{2} \mathrm{CCN}^{-}\right)$, in contrast to 1a, undergoes two hydrogen/deuterium exchanges and does not eliminate $\mathrm{CN}^{-}$despite the fact that cyanide is a much better leaving group than fluoride.

\section{Conclusions}

Vinyl fluoride reacts with a number of strong bases to afford 1-fluorovinyl anion and a hydrogen-bonded cluster between fluoride and acetylene. These ions were identified based upon their reactivity, an independent preparation of $\mathbf{1 a}$, and $a b$ initio molecular orbital calculations. These results, therefore, resolve the apparent discrepancy between Sullivan and Beauchamp [6] and Roy and McMahon [7b] and indicate that both groups were correct. The acidity of vinyl fluoride was measured ( $\left.387 \pm 3 \mathrm{kcal} \mathrm{mol}^{-1}\right)$ and is $22 \mathrm{kcal} \mathrm{mol}^{-1}$ more acidic than ethylene. This unusually large substituent effect can be accounted for by inductive stabilization and geometric changes which minimize electron-electron repulsion. Computations on the 2-fluorovinyl anions have also been carried out, and these species are found to be only slightly less stable than 1a. Both ions appear to be relatively labile with respect to fluoride elimination, but the cis isomer (1c) has a larger computed barrier and appears to be an attractive synthetic target.

\section{Acknowledgments}

Gregg Dahlke provided valuable assistance in carrying out this work. Support from the Minnesota Supercomputer Institute, University of Minnesota McKnight Land Grant Professorship program, National Science Foundation (CHE-8907198), and the donors of the Petroleum Research Foundation, as administered by the American Chemical Society, are gratefully acknowledged.

\section{References}

1. (a) Taft, R. W. Prog. Phys. Org. Chem. 1987, 16, 1-83. (b) Taft, R. W. Prog. Phys. Org. Chem. 1983, 14, 247-350. (c) Taft, R. W.; Koppel, I. A.; Topsom, R. D.; Anvia, F. I. Am. Chem. Soc. 1990, 112, 2047-2052, and references therein.

2. Dahlke, G. D.; Kass, S. R. J. Am. Chem. Soc. 1991, 113, $5566-5573$.

3. Dahlke, G. D.: unpublished results,

4. Lias, S. G.; Bartmess, J. E.; Liebman, J. F; Holmes, J. L.; Levin, R. D.; Mallard, W. G. J. Phys. Chem. Ref. Data 1988, 17, Suppl. 1.

5. Faird, R.; McMahon, T. B. Can. J. Chem. 1980, 58, 2307-2311.

6. Sullivan, 5. A.; Beauchamp, J. L. I. Am. Chem. Soc. 1977, 99, 5017-5022

7. (a) Latson, J. W.; McMahon, T. B. J. Am, Chem. Soc. 1985, 107, 766-773. (b) Roy, M.; McMahon, T. B. Can. J. Chem. 
1985, 63, 708-715. (c) Larson, J. W.; McMahon, T. B. J. Am Chem. Soc. 1983, 105, 2944-2950.

8. Kass, S. R.; Guo, H.; Dahlke, G. D. J. Am. Soc. Mass Spectrom. 1990, 1, 366-371.

9. Caldwell, G.; Bartmess, J. E. Org. Mass Spectrom. 1982, 17, $456-457$

10. (a) Haszeldine, R. N.; Pool, C. R.; Tipping, A. E. J. Chem. Sac. Dalton Trans. 1975, 2177-2181. (b) Drakesmith, F. G. Stewart, O. J.; Tarrant, P. J. Org. Chem. 1968, 33, 472-474.

11. Boeckman, R. K. Jr.; Blum, D. M.; Ganem, B.; Halvey, N Org. Syn. 1978, 58, 152-157.

12. (a) Umemoto, T,; Fukami, S.; Tomizawa, G.; Harasawa, K. Kawada, K.; Tomita, K. J. Am. Chem. Soc. 1990, 112 8563-8575. (b) Umemoto, T.; Tomita, K.; Kawada, K. Org Syn. 1990, 69, 129-143

13. Frisch, M. J.; Head-Gordon, M.; Trucks, G. W.; Foresman J. B.; Schlegel, H. B.; Raghavachari, K.; Robb, M.; Binkley, J. S.; Gonzalez, C.; Defrees, D. J.; Fox, D. J.; Whiteside, R A.; Seeger, R.; Melius, C. F.; Baker, J.; Martin R. L.; Kahn, L. R.; Stewart, J. J. P.; Topiol, S.; Pople, J. A. Caussian 90 Revision F; Gaussian, Inc, Pittsburgh, PA 1990.

14. (a) Hariharan, P. C.; Pople, J. A. Theor. Chim. Acta 1973, 28 , 213-222. (b) Spitznegel, G. W.; Clark, T; Chandrasekhar, J.; Schleyer, P. v. R. J. Comput. Chem. 1982, 3, 363-371. (c) Clark, T.; Chandrasekhar, J.; Spitznegel, G. W.; Schleyer P. v. R. J. Comput. Chem. 1983, 4, 294-301. (d) Moller, C. Plesset, M. S. Phys. Rev. 1934, 46, 618-622. (e) Pople, J. A. Binkley, J. S.; Seeger, R. Int. I. Quantum Chem. Symp. 1976 10, 1-19.
15. Hehre, W. J.; Radom, L.; Schleyer, P. v. R.; Pople, J. A. $A b$ Initio Molecular Orbital Theory; John Wiley \& Sons: New York, 1986.

16. DePuy, C. H. Org. Mass Spectrom. 1985, 20, 556-559.

17. (a) Chou, P. K.; Kass, S. R. J. Am. Chem. Soc. 1991, 113, 4357-4359. (b) O'Hair, R. A. J.; Gronert, S.; DePuy, C. H. Bowie, J. H. J. Am. Chem. Soc. 1989, 111, 3105-3106, and references therein.

18. Ervin, K. M.; Gronert, S.; Barlow, S. E.; Gilles, M. K.; Harrison, A. G.; Bierbaum, V. M.; DePuy, C. H.; Lineberger, W. C.; Ellison, G. B. J. Am. Chem. Soc. 1990, $112,5750-5759$.

19. Wiberg, K. B. I. Org. Chem. 1991, 56, 544-550

20. (a) Herzberg, G. Molecular Spectra and Molecular Structure III. Electronic Spectra and Electronic Structure of Polyatomic Molecules, Van Nostrand: New York, 1966. (b) Huisman, P. A. G.; Mijlhoff, F. C.; Renes, G. H. J. Mol, Struct. 1979, 51 , 191-209. (c) Carlos, J. L. Jr.; Larl, R. R. Jr.; Bauer, S. H. J. Chem. Soc. Faraday Trans. II 1974, 70, 177-187.

21. Graul, S. T.; Squires, R. R. I. Am. Chem. Soc. 1990, 112 2517-2529

22. Chandrakekhar, J.; Andrade, J. G.; Schleyer, P, v. R. J. Am. Chem. Soc. 1981, 103, 5612-5614.

23. (a) Bach, R. D.; Evans, J. C. J. Am. Chem. Soc. 1986, 108, 1374-1379. (b) Caramella, P.; Houk, K. N. Tetrahedron Lett. 1981, 22, 819-822.

24. Ritchie, J. P.; Bachrach, S. M. J. Am. Chem. Soc. 1990, 112, 6514-6517. 